\title{
Comparative analysis of higher education study programs' quality, efficiency and effectiveness
}

\author{
Arhipova, Irina ${ }^{a}$; Paura, Liga ${ }^{\text {; }}$ Eiduks, Janis ${ }^{a}$ and Vitols, Gatis ${ }^{a}$
}

${ }^{\mathrm{a}}$ Faculty of Information Technologies, Latvia University of Agriculture, Latvia.

\begin{abstract}
Many definitions of quality, efficiency and effectiveness exist in literature and can be considered as the relationships between inputs, outputs and outcomes. From this point of view efficiency may be defined simply as the relation of outputs to inputs, effectiveness as the relation of outcomes to outputs and inputs, but quality as a measure of change of outputs and outcomes. The objective of this paper is evaluation of higher education study programs quality, efficiency and effectiveness in the case of Latvia University of Agriculture engineering study programs. The conceptual framework of quality, efficiency and effectiveness was defined, which allow to perform the comparative analyze of the study programs inputs, outputs and outcomes depending on the study year. It is concluded that even the quality, as the change of inputs or outputs, decreases, at the same time the quality, as the change of outcomes, can increase. If the efficiency of study program, as the relation of outputs to inputs, decreases at the same time the effectiveness of the study program, as the relation of outcomes to outputs or inputs, can increase depending on study year.
\end{abstract}

Keywords: Quality; efficiency; effectiveness; inputs; outputs; outcomes. 


\section{Introduction}

Many definitions of quality, efficiency and effectiveness exist in literature, as the result these terms have often been used synonymously and inconsistently (Colby, Witt, 2000). Quality may be defined as the conformance of requirement, being fit to use and its definition depends on the applied context and measures. Quality in higher education is a term that is commonly considered to indicate a high level of all stakeholders, primarily students, satisfaction with obtained suitable results at University (Lupo, 2013).

The term effective is used, when associated concept is adequate to accomplish a purpose, producing the intended or expected result. In turn, efficient term describes performing or functioning in the best possible manner with the least waste of the time and effort. Effectiveness is often referred to as doing the right thing; while efficiency is doing things right (The Pennsylvania State University, 2006).

Quality, efficiency and effectiveness usually are associated with the concepts of outputs, outcomes, process or inputs. Outputs typically refer to changes in student achievement, completion rates, certification, skills, and certain attitudes and values. The outcomes are directly influenced by political choice in the longer time, such as employment, earnings and values. Inputs provide the preconditions for the core transformation process in organisations (Scheerens, Luyten \& van Ravens, 2011) such as characteristics of teaching staff, students, facilities, curriculum, and other resources. Quality is often defined, synonymously with effectiveness, as the degree to which objectives are met or desired levels of accomplishment achieved (Adams, 1993).

The evaluation of quality, efficiency and effectiveness can be considered as the relationships between inputs, outputs and outcomes. From this point of view efficiency may be defined simply as the relation of outputs to inputs, effectiveness as the relation of outcomes to outputs and inputs, but quality as a measure of change of outputs and outcomes.

According to the Europe 2020 strategy Latvia has developed the National Reform Program as part of the growth strategy and has established the purpose to improve the public spending efficiency in higher education and research institutions. The main problem of higher education modernization is the right balance between inputs and relevant outputs (Arhipova, 2014). In research (Paura, Arhipova, 2014) the Latvia University of Agriculture strategic policy to increase the number of enrolled and graduated students has evaluated in respect to the causes of the first year students' dropout rates.

The objective of this paper is evaluation of higher education study programs' quality, efficiency and effectiveness in the case of Latvia University of Agriculture engineering study programs. 


\section{Conceptual framework of quality, efficiency and effectiveness}

One of existing approaches for study program quality evaluation is accreditation to asses of study program's compliance with government regulations. Latvia provides that each higher education institution and study program requires accreditation. According to Latvian legislation specific requirements for the evaluation of a study program are developed (Cabinet of Ministers of the Republic of Latvia, 2015). High school, college and study direction accreditation rules requirements of higher education programs in Latvia consist of seven groups: Study program management; Study program content; Financial and material resources, human resources; Research quality; International cooperation; Quality assurance and Graduated students.

The following input indicators can be defined: financial and material resources (higher educational expenditure per student, proportion of public and private investments, public investment in research and development, percentage of spending on salaries for teaching staff and administrative personnel, higher education institution infrastructure); human resources (teaching staff professional knowledge and skills, working time, career structures, training and certification requirements) and student enrolment data. The output indicators can be defined as scores or proportion of graduated students, test scores, number of research publications, employment statistics, while outcome indicators can be defined as quality of developed skills, graduation rates and drop-out rates.

At the initial step of the evaluation authors offer to use the efficiency and effectiveness simple in the relative term, but the quality in absolute term. In other words, efficiency is the relation of outputs to inputs. Effectiveness is the relation of outcomes to outputs or effectiveness can be defined as the relation of outcomes to inputs, while quality is the change of outputs or outcomes (Fig. 1).

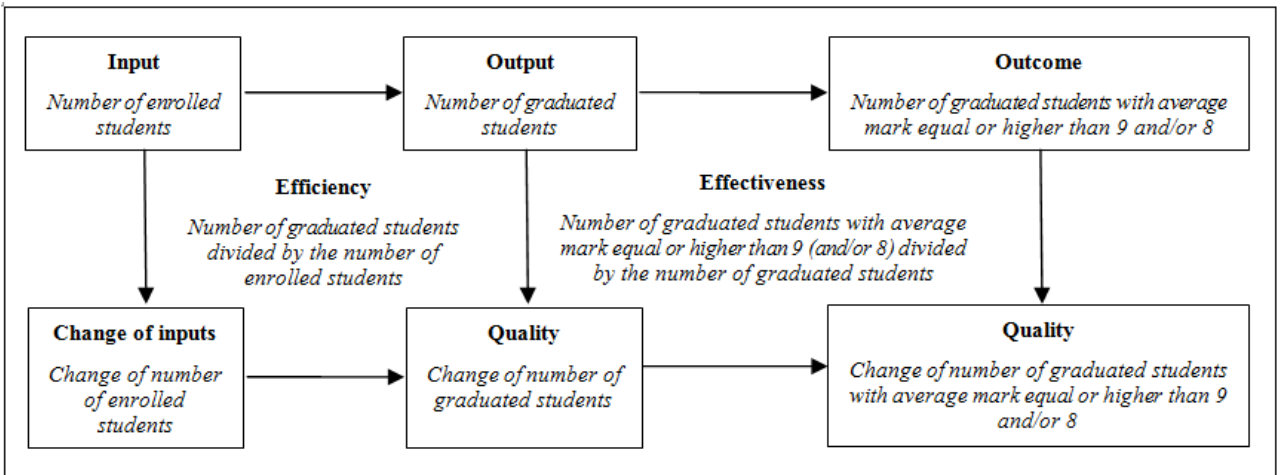

Figure 1. Conceptual framework of study program quality, efficiency and effectiveness with respect to inputs, outputs and outcomes 
The Figure 1 provides the conceptual framework of study program' efficiency and effectiveness with respect to the relationships between inputs, outputs and outcomes (Mandl, Dierx, \&Ilzkovitz, 2008), which is supplemented by additional concept of quality and definitions of the quality, efficiency and effectiveness.

\section{Quality, efficiency and effectiveness of the study programs}

In the process of study program evaluation the learning outcomes for practical study courses should be defined clearly and practically organized. Improving the program quality, it is necessary to organize self-evaluation measurements, where the following indicators for study programs evaluation can be used: student enrolment data for inputs; scores or proportion of graduated students for outputs; and graduation rates, drop-out rates for outcomes. For the study programs comparative evaluation two full-time bachelor study programs "Computer control and computer science" (CCCS) and "Information technology for sustainably development" (ITSD) were chose in Latvia University of Agriculture in case, when students have enrolled in 2011/2012 or 2012/2013 study year, graduated in 2015 or 2016 accordingly and have completed 240 ECTS during four academic years. Table 1 indicates the inputs, outputs and outcomes indicators used in the empirical data analysis and for the calculation of the study programs efficiency scores.

Table 1. Study programs input, output and outcomes indicators

\begin{tabular}{|c|c|c|c|c|}
\hline \multirow{2}{*}{ Indicator } & \multirow{2}{*}{$\begin{array}{l}\text { Study } \\
\text { year }\end{array}$} & \multicolumn{2}{|c|}{ Study program } & \multirow{2}{*}{ Tota } \\
\hline & & CCCS & ITSD & \\
\hline \multirow[t]{2}{*}{ Input: the number of enrolled students } & $2011 / 2012$ & 61 & 30 & 91 \\
\hline & $2012 / 2013$ & 56 & 25 & 81 \\
\hline \multirow[t]{2}{*}{ Output: the number of graduated students } & $2014 / 2015$ & 22 & 10 & 32 \\
\hline & $2015 / 2016$ & 14 & 14 & 28 \\
\hline \multirow{2}{*}{$\begin{array}{l}\text { Outcome 1: the number of graduated students } \\
\text { with average mark equal or higher than } 9\end{array}$} & $2014 / 2015$ & 1 & 0 & 1 \\
\hline & $2015 / 2016$ & 2 & 3 & 5 \\
\hline \multirow{2}{*}{$\begin{array}{l}\text { Outcome } 2: \text { the number of graduated students } \\
\text { with average mark equal or higher than } 8\end{array}$} & $2014 / 2015$ & 5 & 1 & 6 \\
\hline & $2015 / 2016$ & 2 & 5 & 7 \\
\hline
\end{tabular}


In the quality terms the study programs' input in 2012/2013 study year and output in 2015/2016 are decreased, except for ITSD study program, where the number of graduated students is increased. As opposed the number of graduated students with average mark equal or higher than 9 and/or 8 is increased in 2015/2016, except for CCCS study program, where the number of graduated students with average mark equal or higher than 8 is decreased. It can be concluded, that the total quality of study program as a measure of change of outputs is decreased, but the total quality of study program as a measure of change of outcomes is increased. The quality of the each study program as well as total for two programs is presented in Table 2.

Table 2. Quality of study programs as a measure of change of outputs and outcomes

\begin{tabular}{|c|c|c|c|c|}
\hline \multirow{2}{*}{ Quality } & \multirow{2}{*}{ Study year } & \multicolumn{2}{|c|}{ Study program } & \multirow{2}{*}{ Total } \\
\hline & & CCCS & ITSD & \\
\hline Change of inputs: number of enrolled students & $\begin{array}{l}2011 / 2012 \\
2012 / 2013\end{array}$ & -5 & -5 & -10 \\
\hline Change of outputs: number of graduated students & $\begin{array}{l}2014 / 2015 \\
2015 / 2016\end{array}$ & -8 & +4 & -4 \\
\hline $\begin{array}{l}\text { Change of outcome 1: number of graduated } \\
\text { students with average mark equal or higher than } 9\end{array}$ & $\begin{array}{l}2014 / 2015 \\
2015 / 2016\end{array}$ & +1 & +3 & +4 \\
\hline $\begin{array}{l}\text { Change of outcome } 2 \text { : number of graduated } \\
\text { students with average mark equal or higher than } 8\end{array}$ & $\begin{array}{l}2014 / 2015 \\
2015 / 2016\end{array}$ & -3 & +4 & +1 \\
\hline
\end{tabular}

According the proposed definition efficiency is the relation of outputs to inputs or efficiency of the study programs is equal number of graduated students divided by the number of enrolled students. As the results the efficiency of the CCCS study program in 2015/2016 study year is decreased, but the efficiency of the ITSD study program is increased. The total efficiency of both study programs in 2015/2016 study year slightly less than in previous study year (Table 3). 
Table 3. Efficiency of study programs as the relation of outputs to inputs

\begin{tabular}{lllll}
\hline \multirow{2}{*}{ Efficiency } & Study year & \multicolumn{2}{c}{ Study program } & \multirow{2}{*}{ Total } \\
\cline { 3 - 4 } & & CCCS & ITSD & \\
\hline $\begin{array}{lllll}\text { The number of graduated students divided by } \\
\text { the number of enrolled students }\end{array}$ & $2014 / 2015$ & $36.1 \%$ & $33.3 \%$ & $35.2 \%$ \\
& $2015 / 2016$ & $25.0 \%$ & $56.0 \%$ & $34.6 \%$ \\
\hline
\end{tabular}

Effectiveness is the relation of outcomes to outputs or effectiveness of the study programs is number of graduated students with average mark equal or higher than 9 and/or 8 divided by the number of graduated students. It is concluded that the effectiveness of the CCCS study program is increased in the case for the graduated students with average mark equal or higher than 9 and decreased for the graduated students with average mark equal or higher than 8 . At the same time the effectiveness of the ITSD study program is increased in both cases. The total effectiveness of two study programs is increased. The study programs effectiveness as the relation of outcomes to outputs depending on study year is given in Table 4.

Table 4. Effectiviness of study programs as the relation of outcomes to outputs

\begin{tabular}{|c|c|c|c|c|}
\hline \multirow{2}{*}{ Effectiviness } & \multirow{2}{*}{ Study year } & \multicolumn{2}{|c|}{ Study program } & \multirow{2}{*}{ Total } \\
\hline & & CCCS & ITSD & \\
\hline $\begin{array}{l}\text { The number of graduated students with average } \\
\text { mark equal or higher than } 9 \text { divided by the } \\
\text { number of graduated students }\end{array}$ & $\begin{array}{l}2014 / 2015 \\
2015 / 2016\end{array}$ & $14.3 \%$ & $21.4 \%$ & $\begin{array}{l}3.1 \% \\
17.9 \%\end{array}$ \\
\hline $\begin{array}{l}\text { The number of graduated students with average } \\
\text { mark equal or higher than } 8 \text { divided by the } \\
\text { number of graduated students }\end{array}$ & $\begin{array}{l}2014 / 2015 \\
2015 / 2016\end{array}$ & $22.7 \%$ & $10.0 \%$ & $\begin{array}{l}18.8 \% \\
25.0 \%\end{array}$ \\
\hline
\end{tabular}

Using the effectiveness as the relation of outcomes to inputs or effectiveness of the study programs is defiend as the number of graduated students with average mark equal or higher than 9 and/or 8 divided by the number of enrolled students it is concluded that the effectiveness of the CCCS study program is increased in the case for the graduated students with average mark equal or higher than 9 and decreased for the graduated students with average mark equal or higher than 8 . At the same time the effectiveness of the ITSD study program is increased in the both cases as well the total effectiveness of the two study programs also is increased (Table 5). 
Arhipova, I.; Paura, L.; Eiduks, J.; Vitols, G.

Table 5. Effectiviness of study programs as the relation of outcomes to inputs

\begin{tabular}{|c|c|c|c|c|}
\hline \multirow{2}{*}{ Effectiviness } & \multirow{2}{*}{ Study year } & \multicolumn{2}{|c|}{ Study program } & \multirow{2}{*}{ Total } \\
\hline & & CCCS & ITSD & \\
\hline $\begin{array}{l}\text { The number of graduated students with average } \\
\text { mark equal or higher than } 9 \text { divided by the } \\
\text { number of enrolled students }\end{array}$ & $\begin{array}{l}2014 / 2015 \\
2015 / 2016\end{array}$ & $3.6 \%$ & $12.0 \%$ & $\begin{array}{l}1.1 \% \\
6.2 \%\end{array}$ \\
\hline $\begin{array}{l}\text { The number of graduated students with average } \\
\text { mark equal or higher than } 8 \text { divided by the } \\
\text { number of enrolled students }\end{array}$ & $\begin{array}{l}2014 / 2015 \\
2015 / 2016\end{array}$ & $\begin{array}{l}8.2 \% \\
3.6 \%\end{array}$ & $20.0 \%$ & $\begin{array}{l}6.6 \% \\
8.6 \%\end{array}$ \\
\hline
\end{tabular}

The summary of the study programs quality, efficiency and effectiveness tends to increase or decrease with respect to the relationships between inputs, outputs and outcomes is given in the Table 6, where input is defined as the number of enrolled students, output as the number of graduated students, outcome 1 as the number of graduated students with average mark equal or higher than 9 and outcome 2 as the number of graduated students with average mark equal or higher than 8 .

Table 6. Summary of the study programs quality, efficiency and effectiveness tends to increase $(\uparrow)$ or decrease $(\downarrow)$ with respect to the relationships between inputs, outputs and outcomes.

\begin{tabular}{lccc}
\hline \multicolumn{1}{c}{ Study programs } & CCCS & ITSD & Total \\
\hline Quality as change of inputs & $\downarrow$ & $\downarrow$ & $\downarrow$ \\
Quality as change of outputs & $\downarrow$ & $\uparrow$ & $\downarrow$ \\
Quality as change of outcomes 1 & $\uparrow$ & $\uparrow$ & $\uparrow$ \\
Quality as change of outcomes 2 & $\downarrow$ & $\uparrow$ & $\uparrow$ \\
Efficiency as the relation of output to input & $\downarrow$ & $\uparrow$ & $\downarrow$ \\
Effectiveness as the relation of outcome 1 to output & $\uparrow$ & $\uparrow$ & $\uparrow$ \\
Effectiveness as the relation of outcome 2 to output & $\downarrow$ & $\uparrow$ & $\uparrow$ \\
Effectiveness as the relation of outcome 1 to input & $\uparrow$ & $\uparrow$ & $\uparrow$ \\
Effectiveness as the relation of outcome 2 to input & $\downarrow$ & $\uparrow$ & $\uparrow$ \\
\hline
\end{tabular}


Therefore it can be is concluded that even the quality, as the change of input or output decreases, at the same time the quality, as the change of outcome, can increase. If the efficiency of study program, as the relation of output to input, decreases at the same time the effectiveness of the study program, as the relation of outcome to output or input, can increase depending on study year. The evaluation of quality, efficiency and effectiveness should be provided under the common framework as the relationships between inputs, outputs and outcomes.

\section{Conclusions}

The evaluation of quality, efficiency and effectiveness can be considered as the relationships between inputs, outputs and outcomes. From this point of view efficiency may be defined simply as the relation of outputs to inputs, effectiveness as the relation of outcomes to outputs and inputs, but quality as a measure of change of outputs and outcomes.

The conceptual framework of quality, efficiency and effectiveness allow to perform the comparative analyze of the student learning inputs, outputs and outcome depending on the study year.

The study programs inputs, outputs and outcome have analyzed and the comparative analyze of student learning in the engineering study programs of Latvia University of Agriculture was made. It is concluded that even the quality, as the change of input or output, decreases, at the same time the quality, as the change of outcome, can increase. If the efficiency of study program, as the relation of output to input, decreases at the same time the effectiveness of the study program, as the relation of outcome to output or input, can increase depending on study year.

The evaluation of quality, efficiency and effectiveness should be provided under the common framework as the relationships between inputs, outputs and outcomes.

\section{References}

Adams, D. (1993). Defining educational quality. Improving Educational Quality Project, Publication n1: Biennial Report, Arlington, VA: Institute for International Research.

Arhipova, I. (2014). Analysis of the efficiency of Latvia research institutions public spending. Procedia - Social and Behavioral Sciences, 109, 24-28.

Colby, J., Witt, M. (2000). Defining Quality in Education. UNICEF Working Paper Series, United Nations Children's Fund, No. UNICEF/PD/ED/00/02, New York, 1-44.

Doing the Right Things Right: Enhanced Effectiveness and Cost Savings. (2006). Innovation Insight Series, 6, The Pennsylvania State University, 1-4. 
High school, college and study direction accreditation rules. (2015). Rules of the Cabinet of Ministers of the Republic of Latvia No.407, Riga, Latvia.

Lupo, T. (2013). A fuzzy ServQual based method for reliable measurements of education quality in Italian higher education area. Expert Systems with Applications, 40(17), 7096-7110.

Mandl, U., Dierx, A., Ilzkovitz, F. (2008). The effectiveness and efficiency of public spending, Economic papers, 301, European Commission Directorate-General for Economic and Financial Affairs, 1-34.

Paura, L., Arhipova, I. (2014). Cause analysis of students' dropout rate in higher education study program. Procedia - Social and Behavioral Sciences, 109, 1282-1286.

Scheerens, J., Luyten, H., van Ravens, J. (2011). Perspectives on educational quality. Illustrative Outcomes on Primary and Secondary Schooling in the Netherlands. Springer. 